\title{
Self-care programmes for people living with leprosy: a scoping review
}

\author{
Onaedo Ilozumba ${ }^{\text {a }}$ \& Richard J. Lilford ${ }^{\mathrm{a}}$ \\ ${ }^{\mathrm{a}}$ Institute of Applied Health Research, College of Medical and Dental \\ Sciences, University of Birmingham, Edgbaston, Birmingham B15 2TT, UK
}

Submitted 19 November 2021; Accepted 24 November 2021

\begin{abstract}
Summary
Objective Effective self-care is a key approach for the management and prevention of ulcers for people living with leprosy. Understanding the complexities related to the design and implementation of self-care interventions is key to improving future interventions. The aim of this scoping review is to synthesize the existing evidence on self-care for the prevention and management of ulcers amongst people living with leprosy.

Methods We conducted a scoping review using PubMed, Web of Science and Infolep. Studies were included in the review if they reported on a self-care intervention and if they: (i) included individuals living with leprosy (ii) reported on leprosy specific selfcare activities (iii) reported on the development, implementation and evaluation of self-care programs.

Results The initial search identified 476 articles from the three databases and 15 articles fulfilled our eligibility criteria. The self-care programs and interventions were conducted in eight low and middle-income countries. All interventions included were developed by 'organizing authorities' external to the community including governmental and non-governmental organizations. Interventions included education and training either directly with people living with leprosy or with health workers who implemented the intervention. Seven studies reported on clinical outcomes defined as reductions or healing of cracks, wounds or ulcers on hands and feet. A control group was only included in one study and the quality of intervention data varied greatly.

Conclusion While this review suggests that self-care interventions for leprosy contribute to improved prevention and management of wounds, they must be interpreted with caution and additional research is needed.
\end{abstract}

Keywords: Ulcer care, ulcer management, self-care, leprosy

Correspondence to: Onaedo Ilozumba, Institute of Applied Health Research, College of Medical and Dental Sciences, University of Birmingham, Edgbaston, Birmingham, B15 2TT, UK (e-mail: u.ilozumba@bham.ac.uk) 


\section{Introduction}

Self-care can be defined as the range of behaviours undertaken by individuals to promote and restore health. ${ }^{1,2}$ The World Health Organization (WHO) defines self-care as 'the ability of individuals, families and communities to promote health, prevent disease, maintain health, and cope with illness and disability with or without the support of a healthcare provider'. ${ }^{3}$ Notwithstanding this definition, there are difficulties associated in any review of self-care. First, there are many other definitions apart from the above. ${ }^{2,4,5}$ Second, there is overlap between self-care and other concepts such as self-management, self-monitoring, self-treatment, self-efficacy, peer-support that tap into the same or similar underlying constructs.

The predominant terms used to identify the above construct vary by field. While reviews on heart failure ${ }^{6-8}$ relate to self-care, those in HIV, ${ }^{9-12}$ diabetes, ${ }^{13-16}$ chronic illnesses ${ }^{17,18}$ and stroke $^{19,20}$ refer to self-management. However, there has been no systematic review on selfcare interventions specifically for leprosy. A related review was performed by Casado et al. ${ }^{21}$ but they specifically focused on community-based programs for people with leprosy. Given that self-care interventions can occur in settings other than the community, we argue that a review specific to self-care is needed. The aim of this review therefore, is to synthesize the existing evidence on self-care for the prevention and management of ulcers amongst people living with leprosy. Casado's review also included self-help by which we mean interventions based on or including some type of economic empowerment, such as micro-finance. In this review we concentrate on interventions where self-care was the main aim of the intervention.

\section{Methods}

We used the framework derived by Levac et $a .^{22}$ to determine the stages of our review.

FRAMEWORK STAGE ONE: IDENTIFYING THE RESEARCH QUESTION

For this scoping review, we adopted a broad research question: what is the existing evidence on self-care for the prevention and management of ulcers amongst people living with leprosy?

\section{FRAMEWORK STAGE TWO: IDENTIFYING RELEVANT STUDIES}

PubMed, Web of Science and Infolep were searched for all relevant literature published before 27 th July 2021. Search terms were self-care and leprosy (Table 1). Reference lists of included articles were also hand-searched for additional references.

\section{FRAMEWORK STAGE THREE: STUDY SELECTION}

Studies were included in the review if they:

(i) Included individuals living with leprosy who had participated in a self-care program

(ii) Reported on leprosy specific self-care activities (e.g. visual inspection of the skin and limbs) and or the clinical outcomes (e.g. site and number of wounds)

(iii) Reported on the development, implementation or evaluation of self-care programs.

The first author (OI) conducted title and abstract screening of all included papers and another researcher (see acknowledgements) performed a duplicate review of $20 \%$ of all titles and abstracts. 


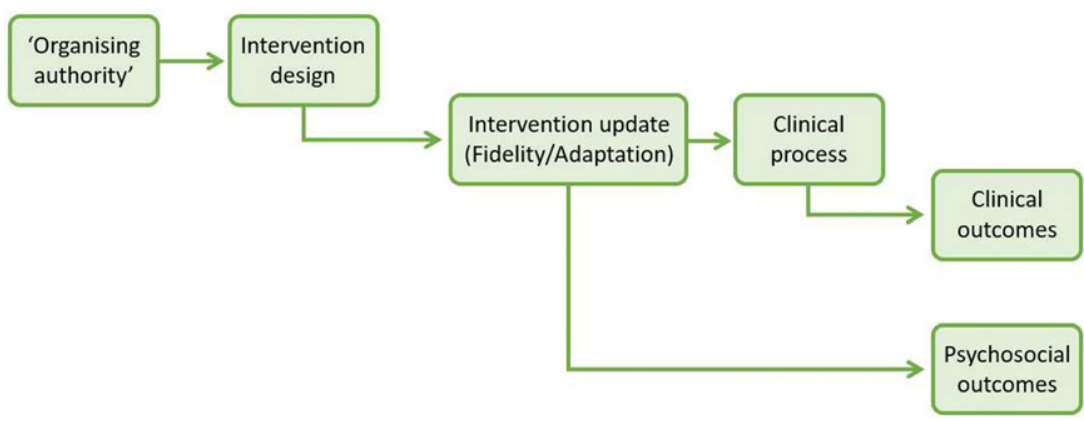

Figure 1. Framework for evaluating self-care in leprosy interventions.

Table 1. Search strategy for papers on self-care in leprosy

('self care'[MeSH Terms] OR ('self'[All Fields] AND 'care'[All Fields]) OR 'self care'[All Fields] OR (('self care'[MeSH Terms] OR ('self'[All Fields] AND 'care'[All Fields]) OR 'self care'[All Fields]) AND ('group s'[All Fields] OR 'grouped'[All Fields] OR 'grouping'[All Fields] OR 'groupings'[All Fields] OR 'groups'[All Fields] OR 'groups s'[All Fields] OR 'population groups'[MeSH Terms] OR ('population'[All Fields] AND 'groups'[All Fields]) OR 'population groups'[All Fields] OR 'group'[All Fields])) OR 'self-help'[All Fields]) AND ('leprosies'[All Fields] OR 'leprosy'[MeSH Terms] OR 'leprosy'[All Fields] OR (('leprosies'[All Fields] OR 'leprosy'[MeSH Terms] OR 'leprosy'[All Fields]) AND ('ulcer'[MeSH Terms] OR 'ulcer'[All Fields] OR 'ulcerate'[All Fields] OR 'ulcerated'[All Fields] OR 'ulcerates'[All Fields] OR 'ulcerating'[All Fields] OR 'ulceration'[All Fields] OR 'ulcerations'[All Fields] OR 'ulcerative'[All Fields] OR 'ulcers'[All Fields] OR 'ulcer s'[All Fields] OR 'ulcerous'[All Fields])) OR ('foot ulcer'[MeSH Terms] OR ('foot'[All Fields] AND 'ulcer'[All Fields]) OR 'foot ulcer'[All Fields] OR ('foot'[All Fields] AND 'ulcers'[All Fields]) OR 'foot ulcers'[All Fields]))

\section{FRAMEWORK STAGE FOUR: CHARTING THE DATA}

During full-text reading, data were extracted using a piloted data extraction form that included information such as author, date, study aim/objective/research question, setting, intervention design, sample description, general and clinical outcomes.

FRAMEWORK STAGE FIVE: COLLATING, SUMMARIZING, AND REPORTING THE RESULTS

We adopted a modified version of Lilford et $a l .{ }^{23}$ causal chain for evaluating policy and service interventions. The constructs of the chain provide us with a framework for summarizing and reporting the review results (Figure 1). As stated, the self-care interventions were designed and implemented by an 'organising authority'. Interventions can be implemented as designed and described with high fidelity or low fidelity and they may undergo adaptations. Intervention implementation results in psychosocial outcomes, such as participation or reduction in stigma and process outcomes, which are related to implementation activities. Additionally, the selfcare intervention can include clinical processes such as foot inspection or the use of protective footwear, which result in clinical outcomes including number and site of ulcers.

\section{Results}

\section{ARTICLE SELECTION (SEE PRISMA DIAGRAM, FIGURE 2)}

The initial search identified 476 articles from the three databases and after the removal of 107 duplicates, 369 articles were screened. After screening, we retrieved 40 full-text articles, 


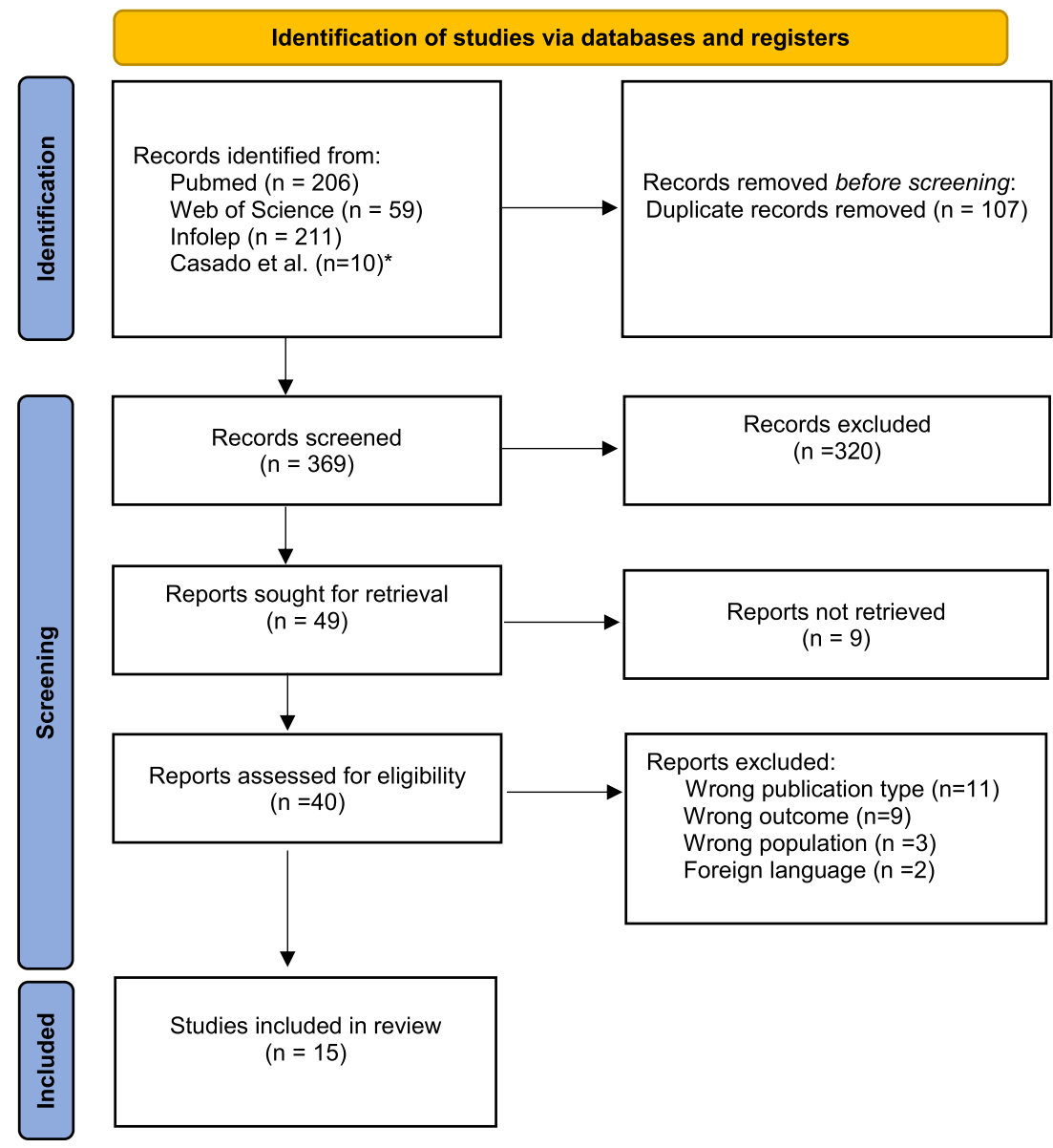

Figure 2. PRISMA flow diagram. *All articles in Casado et al. ${ }^{21}$ were captured by our Pubmed, Web of Science or Infolep searches.

of which 15 articles fulfilled our eligibility criteria. The bibliography of included articles was hand searched for additional references but none was identified, leaving a final list of 15 articles for analysis. Two of these articles ${ }^{24,25}$ reported on the same intervention but over different time scales. We therefore report on a total of 15 articles covering 14 interventions. We compared our yields with the study by Casado et $a .^{21}$ Our search identified all 10 articles which were classified as self-care by Casado et al. ${ }^{21}$ Five of these articles met our inclusion criteria and they had all been included in our review. We identified an additional 10 articles not included in Casado et $a ._{.}{ }^{21}$ The 15 articles were conducted in the following eight countries-China, ${ }^{24-26}$ Ethiopia, ${ }^{27-29}$ Brazil, $^{30}$ Nepal, ${ }^{31,32}$ Nigeria, ${ }^{33,34}$ Indonesia, ${ }^{35,36}$ India $^{37}$ and Mozambique. ${ }^{38}$ All articles but one ${ }^{26}$ were published between 2001 and 2021.

Reviewing the 15 articles, nine studies obtained quantitative data $24-26,28,29,32-34,37$ and the remaining six utilized exclusively qualitative designs. ${ }^{27,30,35,36,38,39}$ Only one of the 9 studies that included quantitative data used a contemporaneous control group and this was not obtained by a process of randomization. ${ }^{32}$ The other eight articles utilized cohort studies in which 
they followed the same group of participants over varying periods of time. ${ }^{24-26,28,29,33,34,37}$ Additional details of the included studies are presented in Table 2.

\section{INTERVENTION DESCRIPTION}

As stated, in all 14 interventions (covering 15 studies), the organizing authorities that initiated and developed the interventions were external organizations rather than the communities themselves. Two interventions were developed by non-governmental organizations, ${ }^{27,32}$ two by governmental bodies, ${ }^{30,34}$ five of the interventions resulted from collaborations between non-governmental organizations and ministries of health $24,26,27,37,38$ and the remaining five interventions were developed by research teams. ${ }^{28-31,36}$

\section{DESCRIPTION OF SELF-CARE INTERVENTIONS}

All 14 interventions involved implementing self-care programs in communities or healthcare centers and training health care workers and people living with leprosy. Nine of the interventions included the formation of self-care groups in which people living with leprosy learned about wound care and management among other topics such as general hygiene. ${ }^{27,30,31,33-38}$ In two further interventions, self-care programs were only delivered to individuals who were formed into self-care groups. ${ }^{25,26}$ The final three interventions described interventions that were delivered in specific contexts. The first of these, by Cross and Newcombe, ${ }^{32}$ provided self-care training to people living in a purpose built center but did not explicitly create self-care groups. The second study ${ }^{29}$ focused on the family unit and included economic empowerment (via micro-finance loans). The final intervention by Hounsome et al. ${ }^{28}$ was integrated across lymphatic filariasis, podoconiosis and leprosy and was targeted at individuals. Additional details on all 14 included interventions are provided in Table 3.

\section{FIDELITY AND ADAPTATION OF INTERVENTIONS}

Five of the 15 studies described an adaptation that was made over the intervention phase..$^{24,26,27,29,36}$ We noted that the training ${ }^{27,29}$ and footwear provision ${ }^{26,36}$ components of the intervention packages were most likely to be adapted. Benbow et al. ${ }^{27}$ made significant changes in their intervention by including training for facilitators during intervention implementation; initially, there was no formal training, but as the programme expanded a fourday 'introduction to self-care' workshop was run, which was later developed further into a four-day training course that focused on facilitation, setting-up and running self-care groups. van't Noordende ${ }^{29}$ faced difficulties in distributing printed training materials which were only distributed after the follow-up assessment had been completed. In regards to footwear adaptations, Smith et al. ${ }^{26}$ could not meet targets related to the provision of moulded footwear or surgical interventions. Additionally, they also had to provide footwear advice to participants who sought to purchase footwear independently of the program. By creating adapted sandals with families and workers from the health office, Syahputri et al. ${ }^{36}$ were able to provide footwear as part of their deformity care package. There were two adaptions noted to the recruitment or delivery of the intervention. ${ }^{26,29}$ van't Noordende ${ }^{29}$ due to differences in distribution of diseases per district, had to organise different sessions for people living with the three different conditions (lymphatic filariasis, podoconiosis and leprosy) and their families. In two of the articles, there were difficulties with the delivery of care packages in the intervention. Smith et al. ${ }^{26}$ experienced delays in starting MDT treatment in one area due to lack of clarity on who had permission to authorize treatment. While in Li et al. ${ }^{24}$ health care workers faced two key challenges. First, they found it difficult to detect early nerve function impairment 


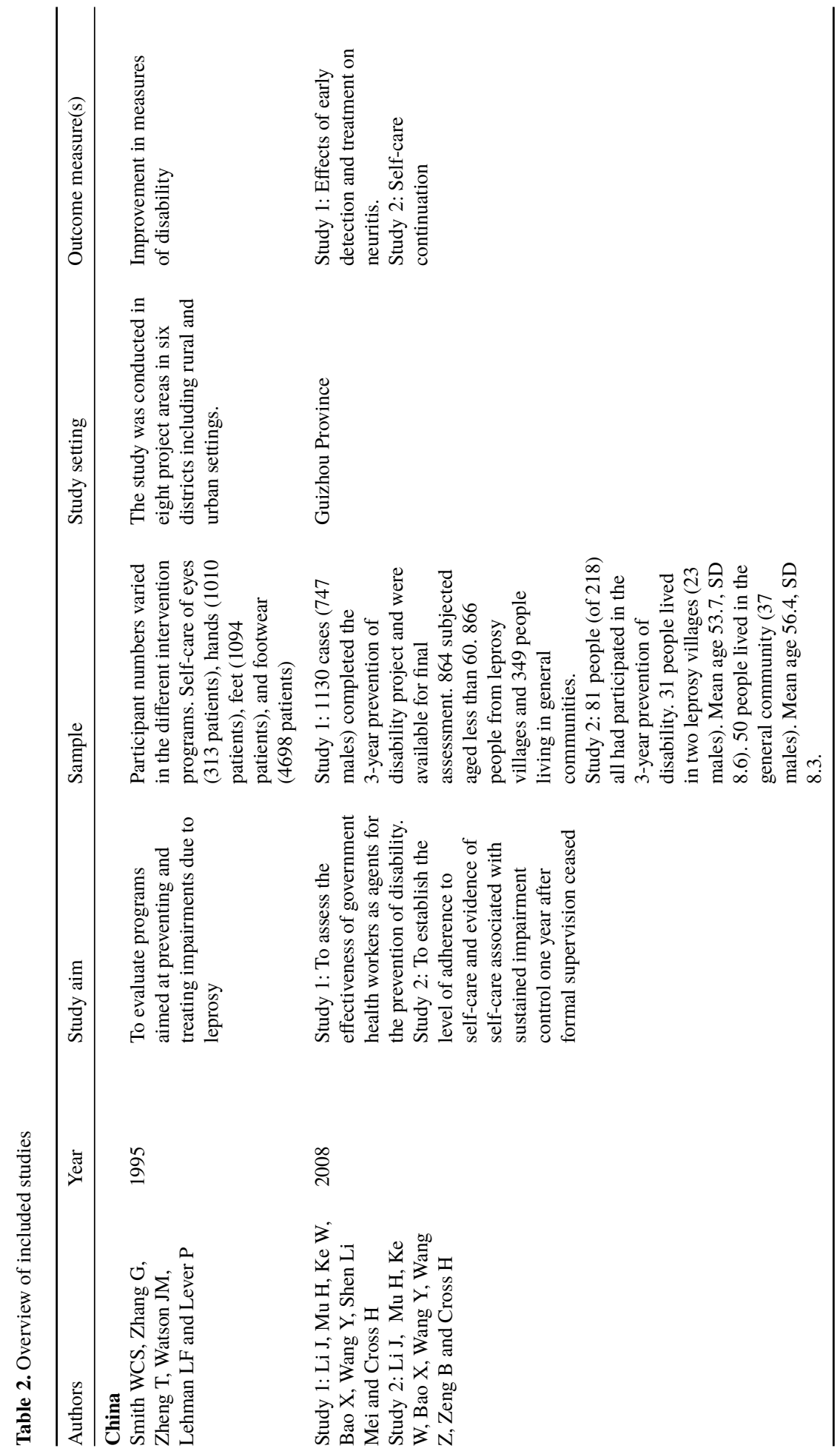


Self-care programmes for people living with leprosy: a scoping review

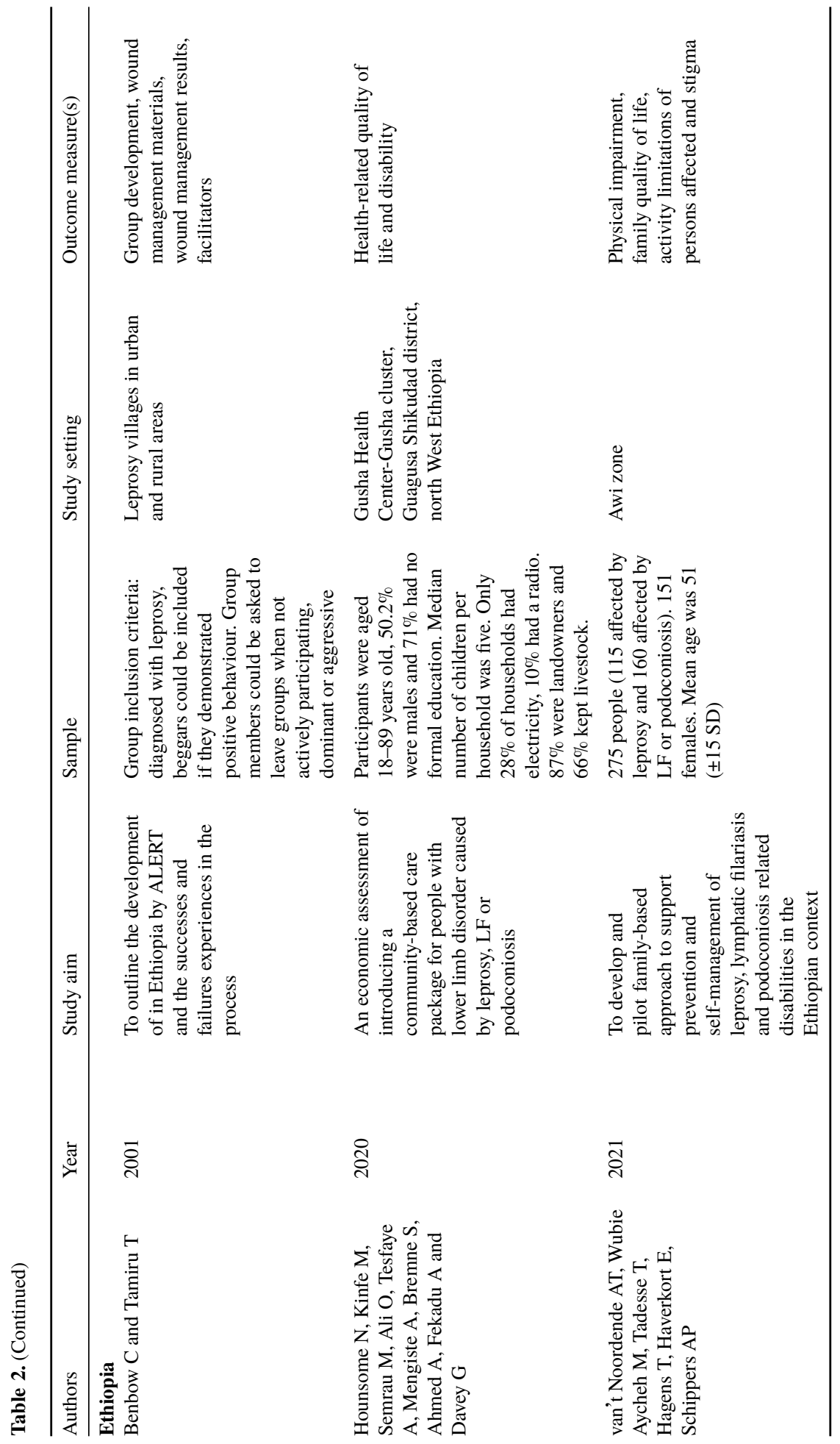




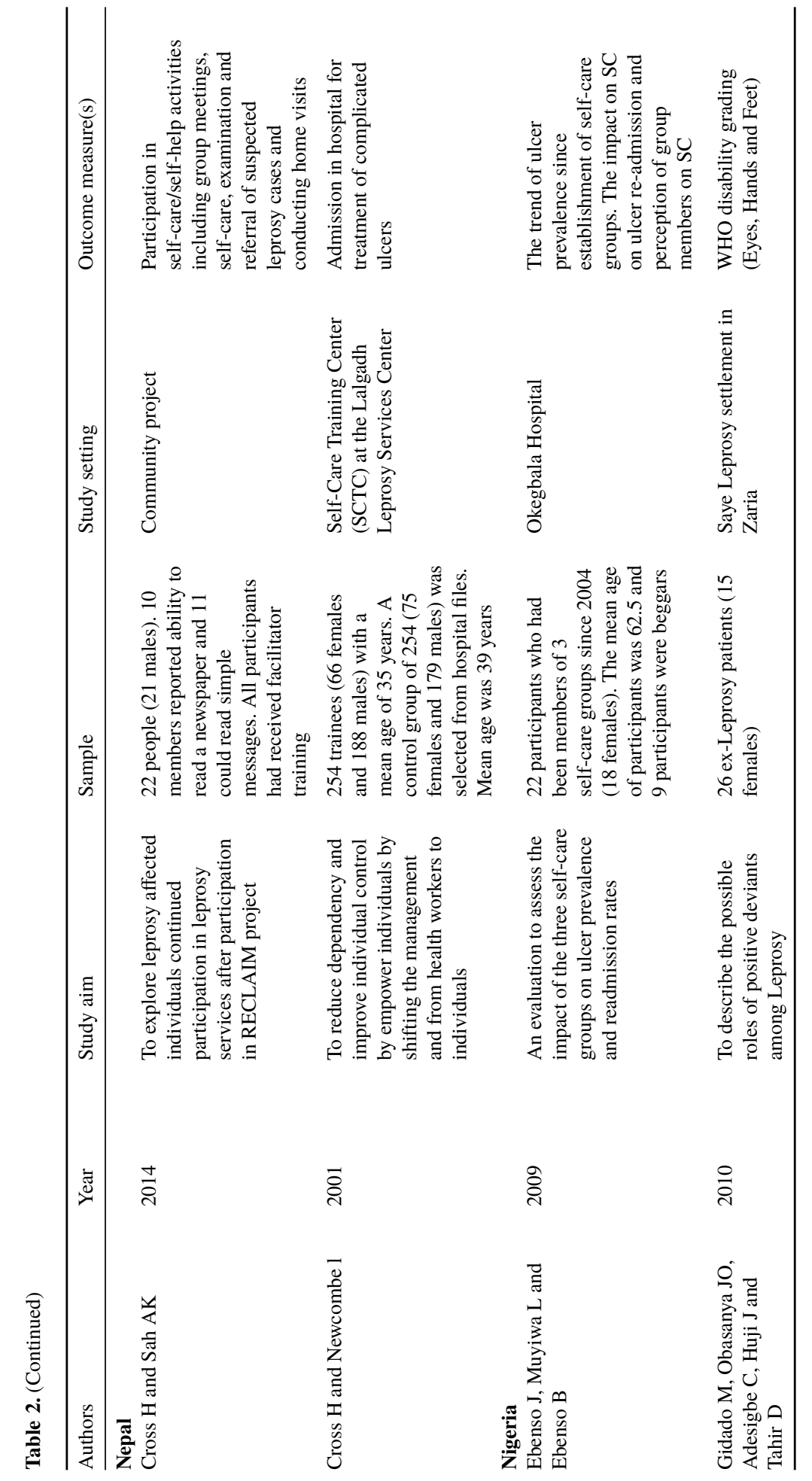


Self-care programmes for people living with leprosy: a scoping review

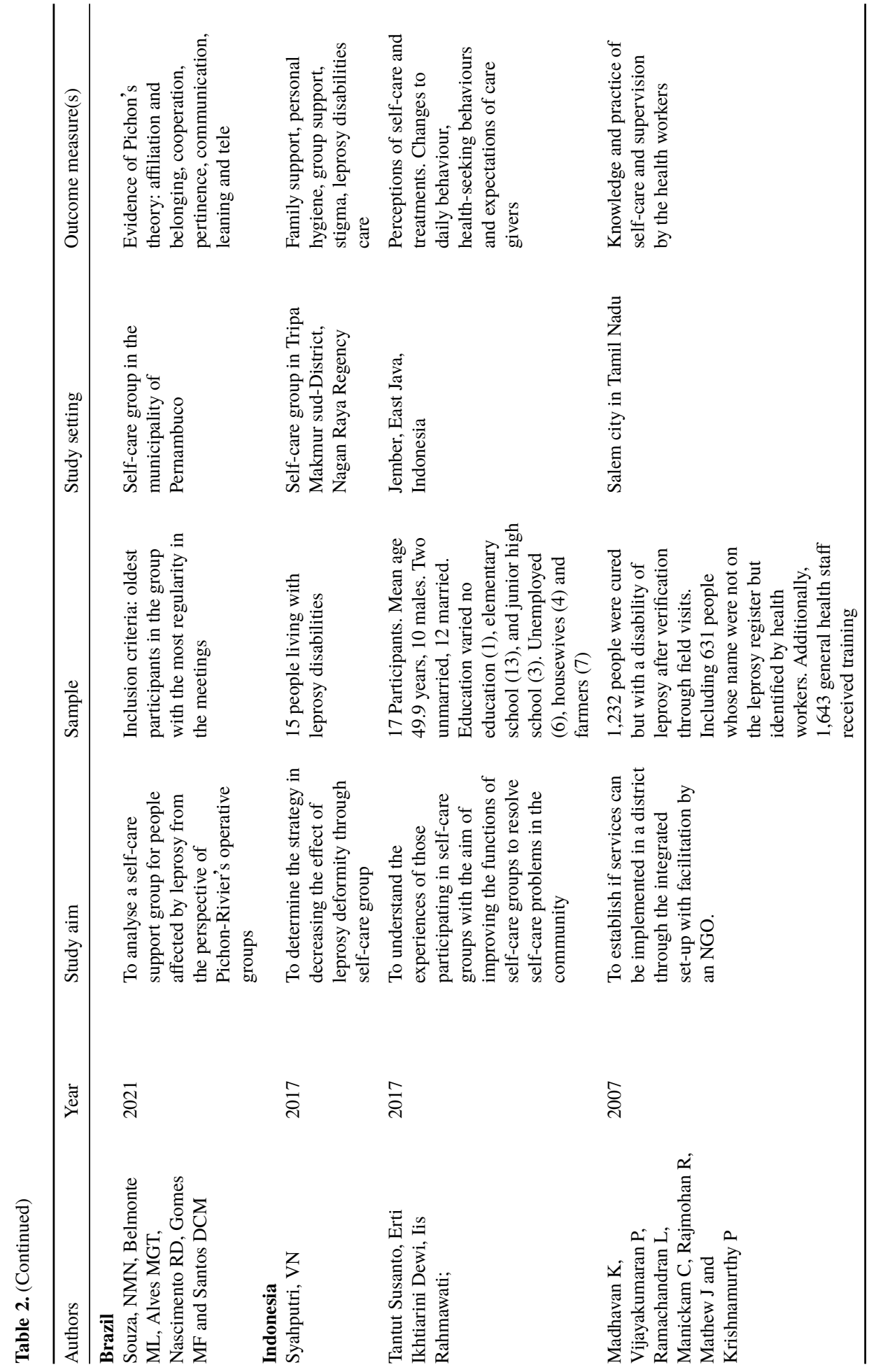




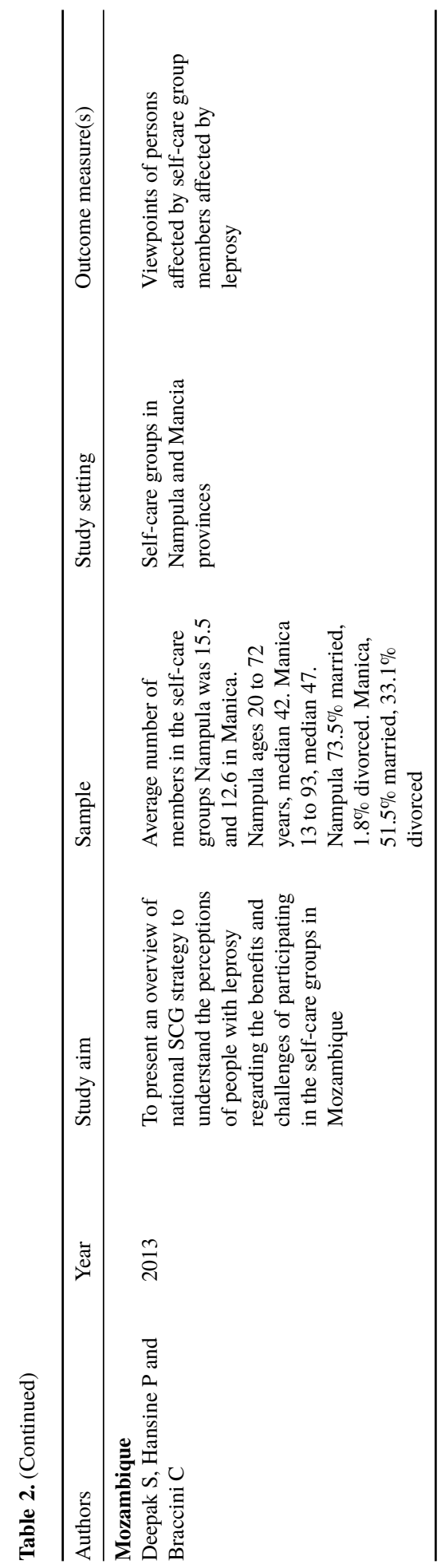




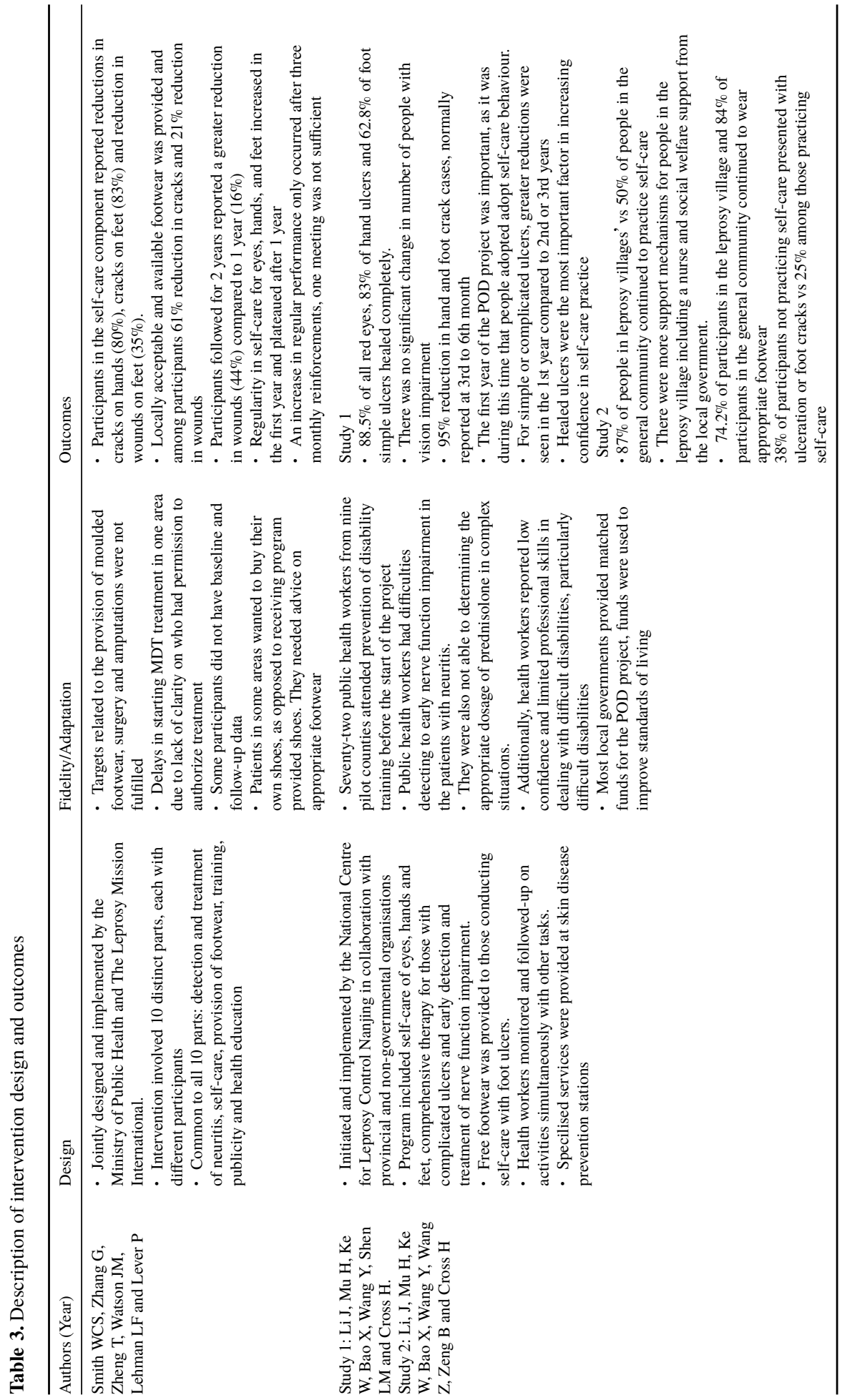




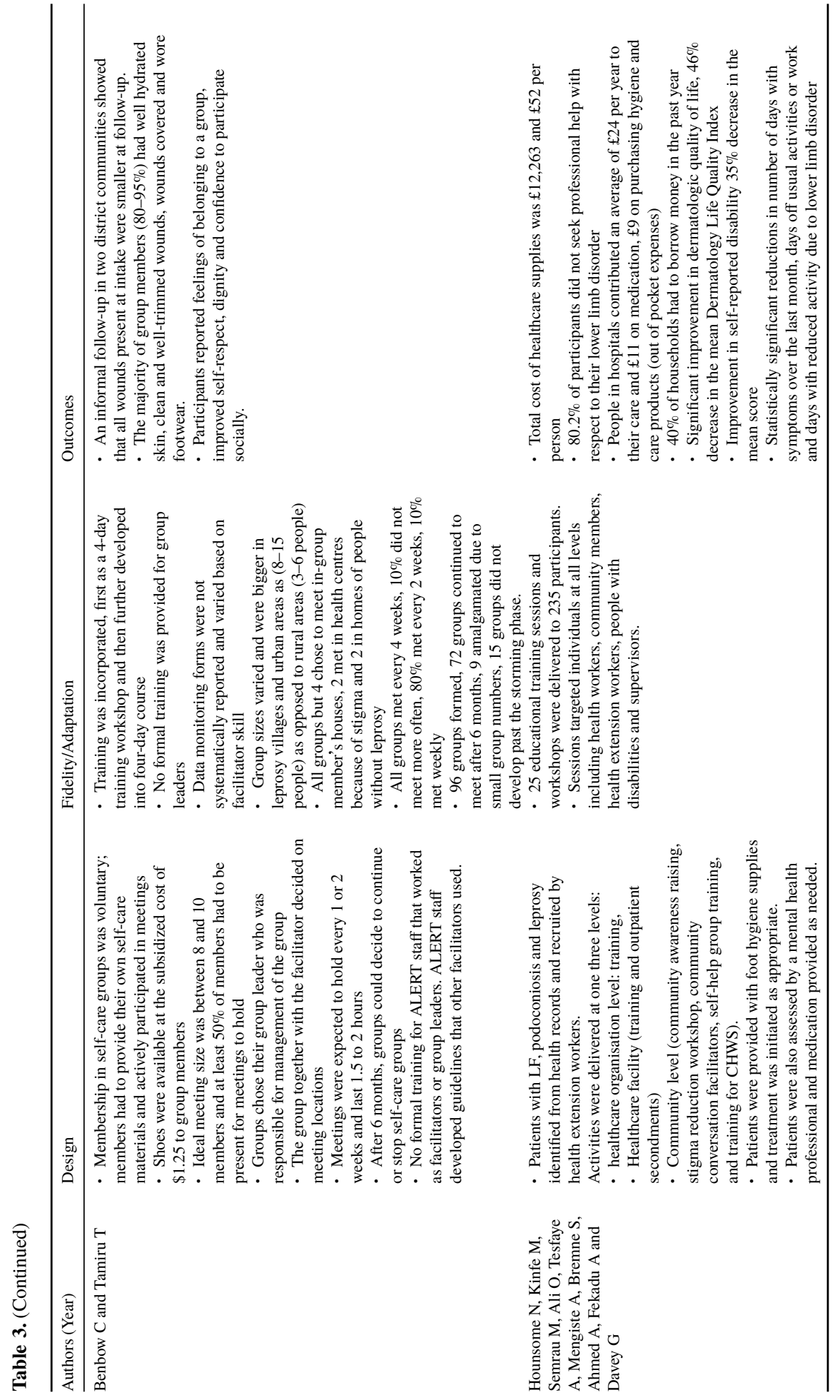




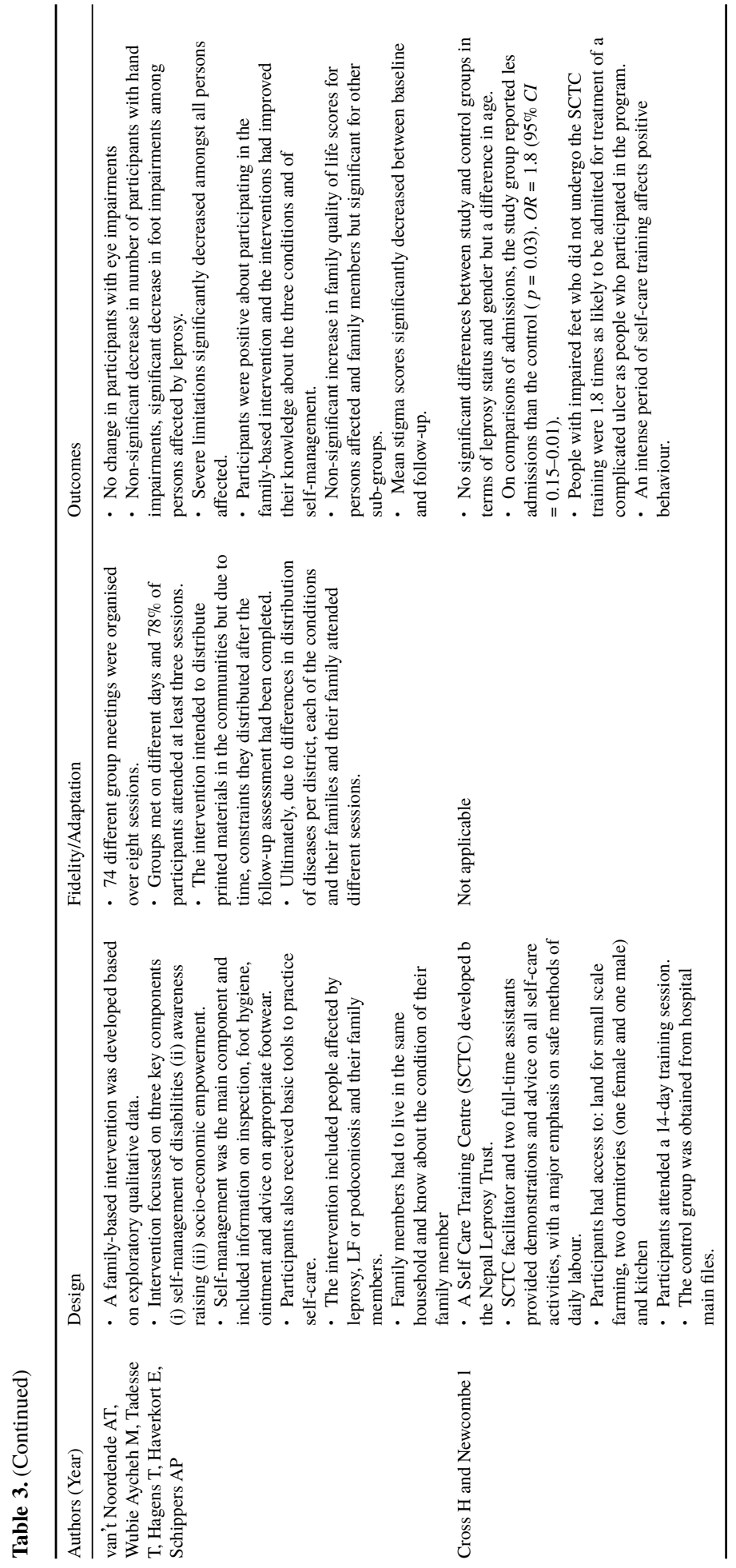




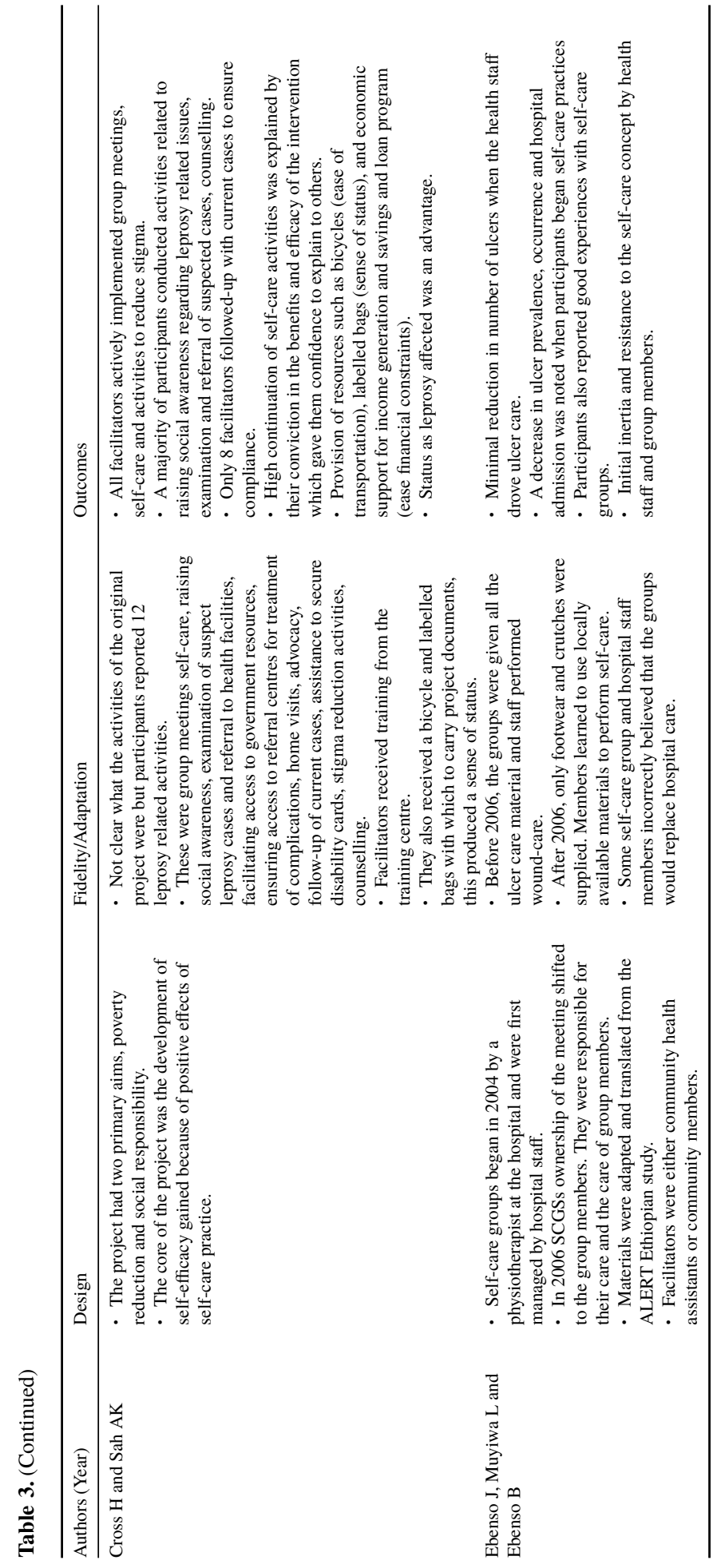


Self-care programmes for people living with leprosy: a scoping review

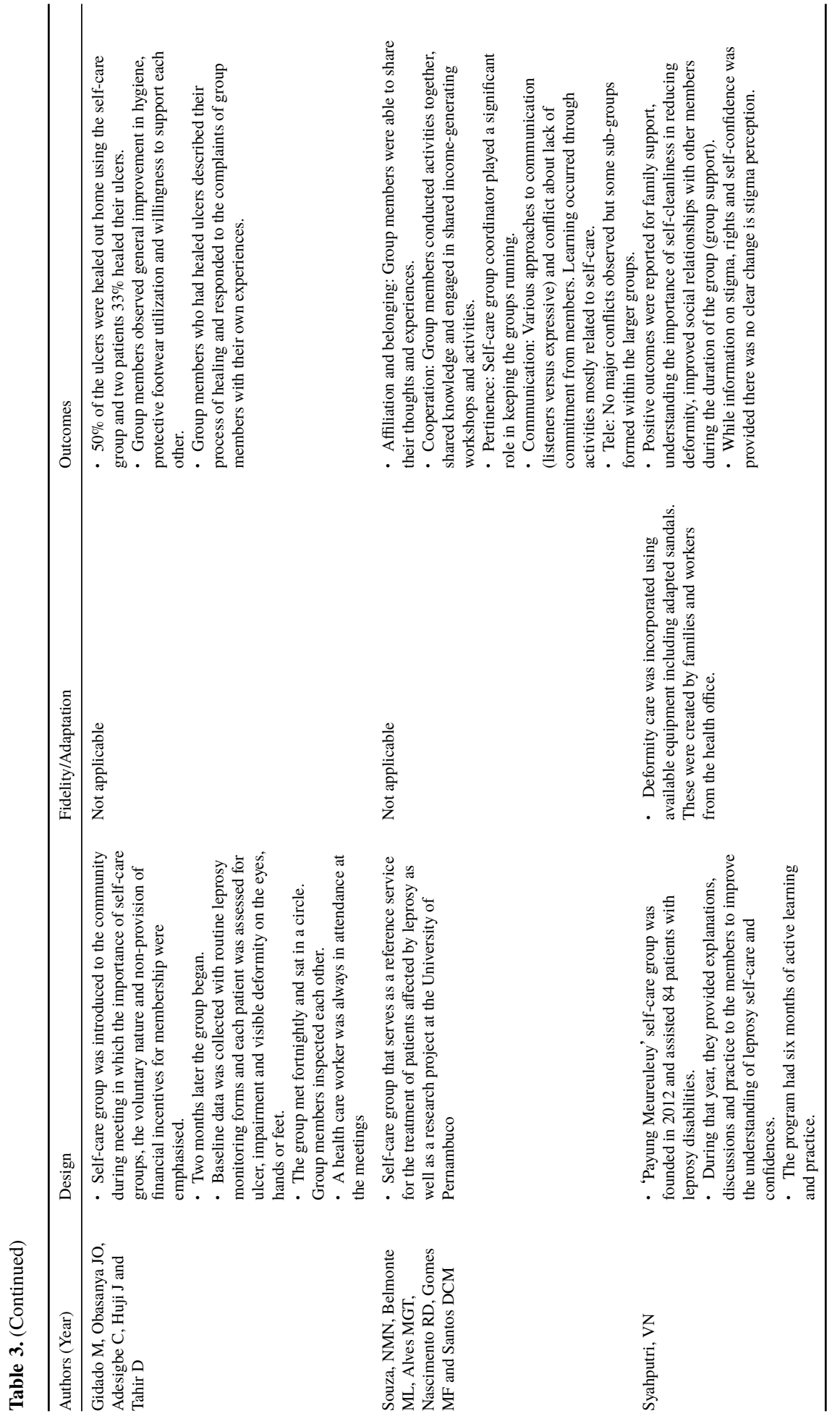




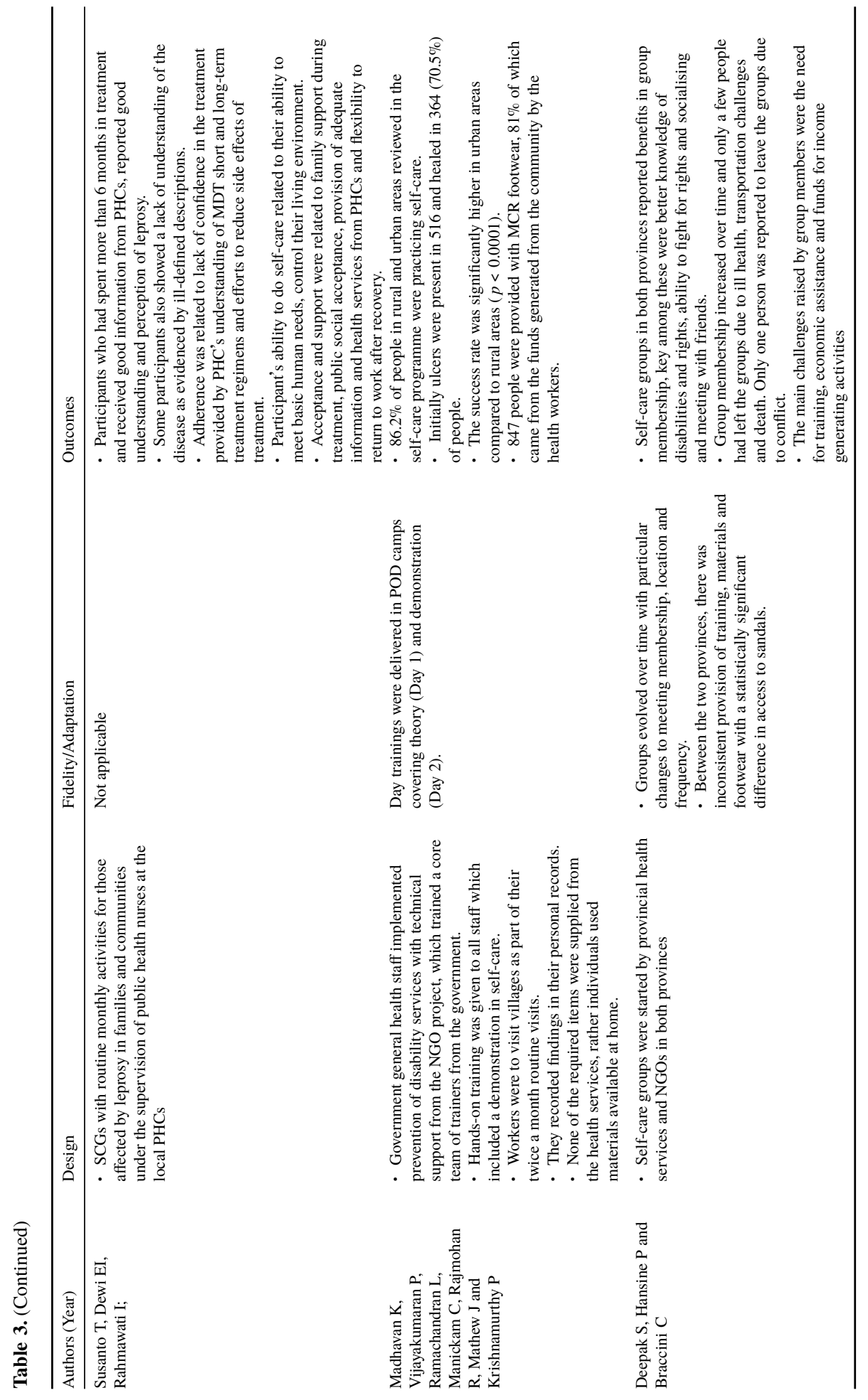


in the patients with neuritis. Second, they were also not able to determine the appropriate dosage of prednisolone in complex situations. Li et al. $^{24}$ also reported a positive adaptation in regards to intervention funding, which involved local government authorities deciding to provide matched funds for the project and to improve the living standards of people living with leprosy.

\section{PROCESS OUTCOMES}

Three articles reported on process level outcomes. ${ }^{26,28,37}$ Madhavan et al. ${ }^{37}$ found that village health nurses (VHN) identified leprosy cases not included on the government leprosy register but noted that transportation was a potential barrier to health workers effectiveness. Smith et $a l .{ }^{26}$ reported on possible dosage effects and found that three monthly reinforcements were needed to produce an improvement in self-care practice. They also found that self-care practice improvement in the first year reduced followed by a plateau in the subsequent two years. Li et $a l .{ }^{24}$ recorded a similar finding with the greatest reductions in simple and complicated ulcers in the first year of the intervention than in the subsequent two years. However, two studies noted continuation of self-care practices. ${ }^{25,26}$

\section{CLINICAL OUTCOMES}

Seven studies reported a clinical outcome and they all reported positive improvement in the number and/or site of lesions on the hands and feet. ${ }^{24-27,29,33,34}$ Smith et al. ${ }^{26}$ reported that because they continuously recruited participants, some of their participants did not contribute to both baseline and follow-up data. The only controlled study (Cross and Newcombe ${ }^{32}$ ) found that an intensive 14-day training course led to an almost 50\% reduction in subsequent admissions among the intervention group. Madhavan et al. ${ }^{37}$ noted ulcer healing in $70 \%$ of participants, with those in urban areas reporting a higher rate of healing than those in rural areas.

\section{PSYCHOSOCIAL OUTCOMES}

Three studies ${ }^{24,26,35}$ highlighted factors that facilitate or impede, self-care practice. Susanto et $a l .{ }^{35}$ found that ability to perform self-care was correlated with a better understanding of leprosy. They also found that factors such as individuals' ability to meet basic human needs and control their living environment were associated with more diligent self-care. ${ }^{35}$

\section{Discussion}

This review synthesized evidence on the implementation of self-care programs for people with leprosy. Our findings suggest that programs which focus on teaching and supporting regular self-care practice report reduction in cracks, wounds, ulcers and hence potentially disability. However, it is important to reflect on our findings in light of the recent review of Casado et $a .^{21}$ as well as challenges and opportunities presented by the study, intervention design and reporting standards of included studies.

First, comparing our review to that of Casado et al. ${ }^{21}$ they included 30 papers which covered self-care groups $(n=10)$, education programs $(n=3)$, livelihood related community intervention programs $(n=6)$, stigma reduction programs $(n=6)$ and interventions related to empowerment $(n=5){ }^{21}$ In our review, we found all 10 of the self-care articles described in the above review, five of which met our inclusion criteria. We also included 9 articles that had not been included. We attribute the inclusion of additional articles to our focus 
on all self-care interventions regardless of setting. This broader scope allowed us highlight additional organisational concerns for self-care interventions. Additional information on organising and managing a self-care program is presented in Celiktemur et al. ${ }^{40}$ However, as in Casado et al. we also noted challenges with study design as well as intervention design, implementation and reporting.

The major flaw in study design was that none of the included interventions utilised the gold standard of a randomized control trial. Randomising people into self-care versus no self-care is not likely to be acceptable to researchers or people. However, there are still many questions about the effectiveness of self-care interventions for example the intensity of programs and individual components of self-care itself. The nine quantitative studies used a cohort rather than repeat cross-sectional design. Thus, they used an extremely weak design where each person acted as their own control and hence where the counterfactual cannot be estimated.

In relation to intervention design, we noted that all programs were conceptualised and implemented by NGOs, ministries or departments of health. While this top-down approach is necessary, where people lack resources and know-how, it is still very important to generate a sense of ownership of self-care interventions. There is substantial evidence in the field of health promotion and health programs which show that community ownership is key in the sustainability of interventions. ${ }^{41-43}$ Some interventions attempted to address ownership by requiring participants to provide their own self-care tools or allowing group members to adapt group meetings as desired.

This review suggests that a key implementation challenge is the availability of human resources needed to deliver the interventions. A recurring problem was the availability of a trained health workforce to conduct home visits and self-care training. The studies also faced issues related to confidence of health care workers, transportation for health workers, availability of wound and ulcer care materials that influenced intervention implementation.

Finally, concerning the reporting of intervention design and implementation, there is a need for further elucidation of self-care interventions. Most articles provided little information on the specifics of the intervention. Gaining in-depth understanding of intervention developer's assumptions and detailed intervention description are important for pragmatic and academic reasons. The lack of detailed descriptions limits the possibility of cross learning between countries and programs. The need for greater description of the intervention group, intervention design and intervention developers' assumptions are included in the recommendations proposed by Jaarsma et ll. $^{44}$

\section{LIMITATIONS}

For this study, a limited search strategy was employed, focusing on only three databases and limiting the search terms to self-care and leprosy. Given the broad range of terminologies used to describe programs that are essentially self-care, we might have missed some relevant studies. However, given that self-care is the primary term utilised in leprosy we decided to explore self-care specific literature.

\section{Conclusion}

The findings of this review suggest that self-care interventions for people with leprosy can lead to reductions in cracks, wounds and ulcers. However, more research is required to address pending questions about the mechanisms by which self-care interventions can accomplish their objectives and be sustainable. Above all more programme designs are needed to test strategies 
to implement self-care programmes in communities (for example self-care versus self-help) and to test various components of the self-care itself (for example different types of footwear).

\section{Ethics approval}

Not required.

\section{Competing interests}

The authors have no competing interests.

\section{Funding}

This research was funded by the National Institute for Health Research (NIHR: 200132) using UK Aid from the UK Government to support global health research. RL is also funded by NIHR ARC West Midlands. The views expressed in this publication are those of the author(s) and not necessarily those of the NIHR or the UK Department of Health and Social Care.

\section{Authors' contributions}

OI: Conducted the literature search and review. OI, RJL: contributed to the development and editing of the manuscript.

\section{Acknowledgements}

We acknowledge Bahadir Celiktemur from The Leprosy Mission England and Wales for his assistance with reviewing abstracts and piloting the data extraction tool. We also acknowledge the support and contribution of other members of the NIHR RIGHT grant team including Jo Sartori and Sopna Choudhury (University of Birmingham).

\section{References}

1 Dean K. Conceptual, theoretical and methodological issues in self-care research. Soc Sci Med, 1989; 29(2): $117-123$.

2 Richard AA, Shea K. Delineation of self-care and associated concepts. J Nurs Scholarsh, 2011; 43(3): $255-264$. doi:10.1111/j.1547-5069.2011.01404.x.

3 World Health Organization. Self-care in the Context of Primary Health Care (No. SEA-HSD-320). Bangkok; 2009.

4 Austen E-O, Webber D, Gnani S, Banarsee R, Mummery D, Majeed A et al. The self-care matrix: a unifying framework for self-care. SelfcaCare, 2019; 10(3): 38-56.

5 Omisakin FD, Ncama BP. Self, self-care and self-management concepts: implications for self-management education. Educ Res, 2011; 2(12): 1733-1737.

6 Clark AM, Spaling M, Harkness K, Spiers J, Strachan PH, Thompson DR et al. Determinants of effective heart failure self-care: a systematic review of patients' and caregivers' perceptions. Heart, 2014; 100(9): 716-721.

7 Graven LJ, Grant JS. Social support and self-care behaviors in individuals with heart failure: An integrative review. Int J Nurs Stud, 2014; 51(2): 320-333.

8 Buck HG, Stromberg A, Chung ML, Donovan KA, Harkness K, Howard AM et al. A systematic review of heart failure dyadic self-care interventions focusing on intervention components, contexts, and outcomes. Int J Nurs Stud, 2018; 77: 232-242.

9 Cooper V, Clatworthy J, Whetham J, Consortium E. mHealth interventions to support self-management in HIV: a systematic review. Open AIDS J, 2017; 11(1): 119-132.

10 Areri HA, Marshall A, Harvey G. Interventions to improve self-management of adults living with HIV on antiretroviral therapy: a systematic review. PLoS One, 2020; 15(5): e0232709.

11 Aantjes CJ, Ramerman L, Bunders JFG. A systematic review of the literature on self-management interventions and discussion of their potential relevance for people living with HIV in sub-Saharan Africa. Patient Educ Couns, 2014; 95(2): 185-200. 
12 Zhang Y, Li X. Uses of information and communication technologies in HIV self-management: A systematic review of global literature. Int J Inf Manage, 2017; 37(2): 75-83.

13 El-Gayar O, Timsina P, Nawar N, Eid W. A systematic review of IT for diabetes self-management: Are we there yet? Int J Med Inform, 2013; 82(8): 637-652.

14 Norris SL, Nichols PJ, Caspersen CJ, Glasgow RE, Engelgau MM, Jack L et al. Increasing diabetes selfmanagement education in community settings: a systematic review. Am J Prev Med, 2002; 22(4): 39-66.

15 Greenwood DA, Gee PM, Fatkin KJ, Peeples M. A systematic review of reviews evaluating technology-enabled diabetes self-management education and support. J Diabetes Sci Technol, 2017; 11(5): 1015-1027. doi:10.117 $7 / 1932296817713506$.

16 Clark M. Diabetes self-management education: a review of published studies. Prim Care Diabetes, 2008; 2(3): 113-120.

17 Gallant MP. The influence of social support on chronic illness self-management: a review and directions for research. Heal Educ Behav, 2003; 30(2): 170-195. doi:10.1177/1090198102251030.

18 Newbould J, Taylor D, Bury M. Lay-led self-management in chronic illness: a review of the evidence. Chronic Illn, 2006; 2(4): 249-261. doi:10.1177/17423953060020040401.

19 Lennon S, McKenna S, Jones F. Self-management programmes for people post stroke: a systematic review. Clin Rehabil, 2013; 27(10): 867-878. doi:10.1177/026921551348104520.

20 Jones F, Riazi A. Self-efficacy and self-management after stroke: a systematic review. Disabil Rehabil, 2011; 33: 797-810. doi:10.3109/09638288.2010.511415.

21 Martos-Casado G, Vives-Cases C, Gil-González D. Scoping review: Community-based programmes with people affected by leprosy. Trop Med Int Heal, 2020; 25(2): 144-158.

22 Levac D, Colquhoun H, O’Brien KK. Scoping studies: advancing the methodology. Implement Sci, 2010; 5(1): 1-9. doi:10.1186/1748-5908-5-69.

23 Lilford RJ, Chilton PJ, Hemming K, Girling AJ, Taylor CA, Barach P. Evaluating policy and service interventions: framework to guide selection and interpretation of study end points. BMJ, 2010; 341(7775): 715-720.

$24 \mathrm{Li} \mathrm{J}, \mathrm{Mu} \mathrm{H}, \mathrm{Ke} \mathrm{W}$, Bao X, Wang Y, Shen LM et al. Government health workers as implementers of prevention of disability measures: an assessment of a prevention of disability project in selected counties of Guizhou Province, People's Republic of China. Lepr Rev, 2008; 79(3): 295-302.

25 Li J, Mu H, Ke W, Bao X, Wang Y, Wang Z et al. The sustainability of self-care in two counties of Guizhou Province, Peoples' Republic of China. Lepr Rev, 2008; 79(1): 110-117.

26 Smith WC, Zhang G, Zheng T, Watson JM, Lehman LF, Levert P. Prevention of impairment in leprosy; results from a collaborative project in China. Int J Lep, 1995; 63(4): 507-517.

27 Benbow C, Tamiru T. The experience of self-care groups with people affected by leprosy: ALERT, Ethiopia. Lepr Rev, 2001; 72: 311-321.

28 Hounsome N, Kinfe M, Semrau M, Ali O, Tesfaye A, Mengiste A et al. Economic assessment of a communitybased care package for people with lower limb disorder caused by lymphatic filariasis, podoconiosis and leprosy in Ethiopia. Trans R Soc Trop Med Hyg, 2020; 114(12): 1021-1034.

29 van't Noordende AT, Aycheh MW, Tadesse T, Hagens T, Haverkort E, Schippers AP. A family-based intervention for prevention and self-management of disabilities due to leprosy, podoconiosis and lymphatic filariasis in Ethiopia: A proof of concept study. PLoS Negl Trop Dis, 2021; 15(2): e0009167.

30 Souza NN, de Belmonte ML, Alves MGT, do Nascimento RD, Gomes MF, dos Santos DCM. Self-care in leprosy from the perspective of operative groups: a qualitative approach. Online Braz J Nurs, 2021; 20: 1-12.

31 Cross H, Kumar Sah A. The experiences and attitudes of people affected by leprosy who voluntarily undertake leprosy services in Nepal. Lepr Rev, 2014; 85(3): 224-231.

32 Cross H, Newcombe L. An intensive self care training programme reduces admissions for the treatment of plantar ulcers. Lepr Rev, 2001; 72: 276-284.

33 Ebenso J, Muyiwa LT, Ebenso BE. Self care groups and Ulcer prevention in Okegbala, Nigeria. Lepr Rev, 2009; 80(2): 187-196.

34 Gidado M, Obasanya J, Adesigbe C, Huji J, Tahir D. Role of positive deviants among Leprosy self-care groups in Leprosy settlement, Zaria, Nigeria. J Community Med Prim Heal Care, 2011; 22: 1-2.

35 Susanto T, Dewi EI, Rahmawati I. The experiences of people affected by leprosy who participated in self-care groups in the community: a qualitative study in Indonesia. Lepr Rev, 2017; 88(4): 543-553.

36 Syahputri VN. Reduction of leprosy disabilities through self-care group "Payung Meureuleuy": a case study in Tripa Makmur sub district, Nagan Raya Regency. Adv Sci Lett, 2017; 23(4): 3507-3510.

37 Madhavan K, Vijayakumaran P, Ramachandran L, Manickam C, Rajmohan R, Mathew J et al. Sustainable leprosy related disability care within integrated general health services: findings from Salem District, India. Lepr Rev, 2007; 78(4): 353-361.

38 Deepak S, Hansine PE, Braccini C. Self-care groups of leprosy-affected people in Mozambique. Lepr Rev, 2013; 84(4): 283-291. 
39 Abera M, Lemma G. The effectiveness of self-care support groups in the prevention and management of ulcer: an evaluation study in Ethiopia. Asia Pacific Disabil Rehabil J, 2003; 14(1): 41-54.

40 Celiktemur B, Choudhury SM, Lilford R. Organizing and managing a programme for self-care in leprosy. Lepr Rev, 2021; 92(4): 338-343.

41 Iwelunmor J, Blackstone S, Veira D, Nwaozuru U, Airhihenbuwa C, Munodawafa D et al. Toward the sustainability of health interventions implemented in sub-Saharan Africa: A systematic review and conceptual framework. Implement Sci, 2016; 11(1): 1-27. doi:10.1186/s13012-016-0392-8.

42 Ishola F, Cekan J. Evaluating the sustainability of health programmes: A literature review. African Eval J, 2019; 7(1): 1-7.

43 Aubel J, Samba-Ndure K. Lessons on sustainability for community health projects. World Health Forum, 1996; 17: $52-57$.

44 Jaarsma T, Strömberg A, Dunbar SB, Fitzsimons D, Lee C, Middleton S et al. Self-care research: How to grow the evidence base? Int J Nurs Stud, 2020; 105: 103555. 